\title{
Letters
}

\section{One fifth of samples of unpasteurised milk are contaminated with bacteria}

Editor-The question of whether unpasteurised ("green top") cows' milk should be banned from retail sale in England and Wales, as it is in Scotland, is being debated. We report microbiological results on 1097 samples of unpasteurised milk bought from 242 retail outlets in England and Wales between May 1996 and July 1997.

The study was to determine the frequency of contamination with potential pathogens and whether statutory tests reflected the presence of these pathogens. Under the Dairy Products Hygiene Regulations 1995, unpasteurised milk for drinking, at the time that it is packaged, must be "free of pathogenic micro-organisms and their toxins in quantities such as to affect the health of the ultimate consumer." In addition, such milk must not contain Staphylococcus aureus $(>500$ organisms/ml) or Escherichia coli. Milk sold direct to the ultimate customer must also not contain coliforms ( $>100$ organisms $/ \mathrm{ml}$ ). The aerobic plate count as a geometric mean over two months should not exceed 50000 organisms $/ \mathrm{ml}$. Milk for pasteurisation must have an aerobic plate count below 300000 organisms $/ \mathrm{ml}$.

Potentially pathogenic bacteria were isolated from 41 of the 1097 samples, from 28 retail outlets. Salmonella was present in five samples (S typhimurium DT104, S dublin, S virchow PT26, $S$ anatum, and both $S$ havana and $S$ ruiru); E coli O157 (verotoxinproducing $E$ coli) in three; campylobacter in 19; Staph aureus (>500 organisms/ml) in 12; and Lancefield groups C or G streptococci $(>100$ organisms $/ \mathrm{ml})$ in two. The eight samples containing $E$ coli $\mathrm{O} 157$ or salmonella came from eight separate retail outlets. The three outlets with samples positive for $E$ coli $\mathrm{O} 157$ stopped selling unpasteurised milk.

A fifth of the samples that did not contain pathogens (163/783) had unacceptable aerobic plate counts or coliform counts. These were from 100 of the retail outlets. Twenty seven samples contained $E$ coli at $>100$ organisms $/ \mathrm{ml}$. The aerobic plate count for 39 samples (33 outlets) exceeded the threshold for pasteurisation. These high counts are unacceptable for unpasteurised milk sold at retail. ${ }^{12}$

Thus one or more samples from 128 of the 242 outlets contained pathogenic bacteria or had aerobic plate counts or coliform counts above acceptable levels. However, 29 of the 41 samples containing potential pathogens, including three containing $E$ coli O157, had satisfactory bacterial counts. Therefore good hygienic quality did not guarantee the absence of pathogens. When our data are coupled with evidence of human illness associated with the consumption of unpasteurised milk, ${ }^{3-5}$ we must conclude that the continuing availability of unpasteurised milk on retail sale constitutes an unacceptable risk to public health.

John de Louvois Head, environmental surveillance unit Anita Rampling Chairman, dairy products working group

Public Health Laboratory Service, London NW9 6EQ

1 Dairy products (hygiene) regulations 1995. London: HMSO, 1995. (Statutory instrument No 1086.$)$

2 Microbiological guidelines for some ready-to-eat foods sampled at the point of sale: an expert opinion from the Public Health Laboratory Service (PHLS). PHLS Microbiol Dig 1996;13:41-3.

3 Public Health Laboratory Service. Submission to the House of Commons agriculture committee enquiry into food safety. Commons agriculture

4 Djuretic T, Wall PG, Nichols G. General outbreaks of infectious intestinal disease associated with milk and dairy products in England and Wales: 1992 to 1996. Commun D products in England and
Rep CDR Rev 1997;7:R41.

Rep CDR Rev 1997;7:R41.
5 Chapman P, Wright P. Untreated milk as a source of vero-

toxigenic E coli O157. Vet Rec 1993;133:171-2.

\section{Ethics and international research}

Placebo trials are unethical for established, untested treatments

EDITOR-In their editorial Halsey et al defended their placebo controlled trials of effective interventions to prevent maternalfetal HIV transmission in developing countries. ${ }^{1}$ Their arguments in defence of these trials are weak. They cite the guidelines of the Council for International Organisations of Medical Sciences, which "call for universal principles of ethical research, not universal standards of medical care." ${ }^{2}$ This does not, however, justify their exposing pregnant women with HIV infection to placebo treatment in a trial that also offers appropriate treatment. Although prevailing economic circumstances in developing countries may preclude such women from routinely receiving effective treatment, this is no justification to deny the control arm in the trial of Halsey et al effective treatment because it would act as an undue incentive. We also do not agree with Lurie and Wolfe's counterarguments that studies supported by the American gov- ernment should provide all participants with the same level of care that is available to Americans. ${ }^{3}$ Although this suggestion is ethically sound and desirable, it is highly impracticable.

We believe that any intervention in a research trial that deliberately sets out not to prevent an anticipated deleterious health condition (maternal-fetal HIV transmission in this case) is unethical and goes against the guidelines of the Council for International Organisations of Medical Sciences. ${ }^{2}$ Examples abound in contemporary medicine of established but untested interventions whose effectiveness cannot now be tested because subjecting people to placebo controlled trials of their effectiveness is considered to be unethical and unacceptable. Lurie and Wolfe's suggestion of comparing the new short course zidovudine regimens against the established ACTG 076 regimen is ethical and statistically sound. Perhaps more appropriate would be a three arm trial, with the new regimens and ACTG 076 making up two arms and the local population of pregnant women infected with HIV who are not actively recruited to the study making up the third (control) arm. The data for this third arm should be readily available locally, and comparisons with the active treatment arms will be valid because they all belong to the same population cohort in which the biological behaviour of the infection is similar. The use of multiple logistic regression, with appropriate adjustments, will enable valid comparisons and conclusions to be made.

It is simplistic of Halsey et al to assert that none of the subjects in their trials are being denied the care that they would otherwise have had. The challenge the trialists have brought themselves is to prove to the world that anyone with understanding would willingly submit themselves to a deleterious health condition in a trial which alternatively offers treatment for that condition. We find the thought that these poor women have been used as human guinea pigs disturbing. If Halsey et al believe that any positive results from their trials in the developing world (to identify cheaper effective treatment to reduce vertical transmission of HIV) will not be exported for the benefit of the developed world, they are probably the only ones on this planet who do.

E C O Edi-Osagie Clinical research fellow, Department of Reproductive Medicine N E Edi-Osagie Specialist registrar, Neonatal Medical Unit

St Mary's Hospital, Manchester M13 0JH

1 Halsey NE, Sommer A, Henderson DA, Black RE Ethics and international research. BMJ 1997;315:965-6. (18 October.) 
2 Council for International Organisations of Medical Sciences-World Health Organisation. International ethical guidelines for biomedical research involving human subjects. Geneva: CIOMS-WHO, 1993.

3 Lurie P, Wolfe SM. Unethical trials of interventions to reduce perinatal transmission of the human immunodeficiency virus in developing countries. $N \mathrm{Engl} J \mathrm{Med}$ 1997;337:853-6

\section{Comparison of short and long zidovudine regimens is appropriate}

EDITOR-In attempting to rebut our charges, ${ }^{1}$ which were supported by editorials in the New England Journal of Medicine ${ }^{2}$ and the Lancet, ${ }^{3}$ that their denying the proved treatment zidovudine to thousands of HIV positive pregnant women in Africa is unethical, Halsey et al quote selectively and misleadingly from relevant ethical guidelines. ${ }^{4}$ These guidelines do not simply require that "no research subjects may be denied care that would otherwise be available for them," ${ }^{4}$ but they proclaim that "the ethical standards applied should be no less exacting than they would be in the case of research carried out in [the sponsoring] country."

In fact, a placebo controlled study in Thailand by the United States Centers for Disease Control and Prevention does not even adhere to the lower standard described by Halsey et al. After zidovudine became available for free to pregnant women who are HIV positive, Thai researchers cancelled their placebo controlled study and gave active treatment to all women; none the less, the Centers for Disease Control and Prevention's study continues (P Phanupak, personal communication).

Recently, we disclosed that researchers from Johns Hopkins University have eliminated the placebo arm of a planned study in Ethiopia. The university sought to justify this change by claiming that preliminary findings from the Centers for Disease Control and Prevention's study in Thailand suggest that the short regimen is working. If Johns Hopkins University has access to enough supposedly confidential and blinded data from the Data Safety Monitoring Board to redesign the Ethiopia study, why does it not make those data public? And why is the university currently planning to start at least one new placebo controlled trial in Uganda?

There is little question that the Centers for Disease Control and Prevention's study in Thailand will show that shorter prepartum durations of zidovudine (4-6 weeks) are more efficacious than placebo. Analysis in 1994 of the data from ACTG 076, the placebo controlled trial that originally showed the efficacy of zidovudine, showed that an average of 7 weeks of prepartum zidovudine was considerably better than placebo in breast feeding women ( $8 \%$ v 23\% perinatal HIV transmission) (R Gelber, personal communication). Thus, comparing the shorter zidovudine regimens with placebo is neither scientifically useful nor ethical; the appropriate comparison is between shorter and longer zidovudine regimens in an equivalency study, as is being done in a study in Thailand funded by the National Institutes of Health.
HIV positive pregnant women whose infants' lives are saved by receiving zidovudine are unlikely to view receiving a life saving drug that they would not be able to afford outside the trial as an "imposition." As one observer has written: "As soon as [researchers] attempt to take advantage of the social predicament in which the subjects are found, they become accomplices to the problem, not observers of it. For usually the investigators have the ability to alter the social deprivation of their particular subjects."

Peter Lurie, Research associate

Sidney M Wolfe Director

Public Citizen, 1600 20th Street, Washington, DC 20009-1001, USA

1 Lurie P, Wolfe SM. Unethical trials of interventions to reduce perinatal transmission of the human immunodeficiency virus in developing countries. $N$ Engl J Med 1997;337:853-6

2 Angell M. The ethics of clinical research in the third world N Engl J Med 1997;337:847-9.

The ethics industry [editorial]. Lancet 1997;350:897.

4 Halsey NE, Sommer A, Henderson DA, Black RE Ethics and international research. BMJ 1997:315:965-6. (18 October.)

5 Rothman DJ. Were Tuskegee and Willowbrook "studies in nature"? Hastings Center Rep 1982 April:5-7.

\section{Zidovudine is too expensive for developing countries}

EDITOR-Halsey et al make some pertinent comments on the realities of health care in many developing nations when they state that research interventions must be appropriate for the country where the research is conducted. ${ }^{1}$ If not, then that country is simply serving as an experimental model for richer nations.

On that very basis, any intervention trial with zidovudine to reduce perinatal transmission of HIV in sub-Saharan Africa (with the possible exception of South Africa) is unethical. As Halsey et al state, annual health care expenditure per capita in these countries is usually less than $\$ 10$. This would pay for only one or two days of treatment with zidovudine once the trial had finished.

Even when trial results are published there is a huge unmet need to disseminate the information to healthcare workers in the regions concerned and to educate them to change practice. Any widespread use of zidovudine in these countries would require the establishment of an efficient drug distribution system to ensure continuity of treatment, continuing medical education of doctors and other healthcare workers, and the provision of laboratory facilities that are currently often unavailable to monitor complications of treatment.

I fear that many of the current zidovudine perinatal intervention trials will fail to improve the health of the population of the country where the trials are performed. Researchers, pharmaceutica companies, and interested health organisations need to look again at the ethics of their research in people of poorer nations.

Justin Burdon Medical officer

Centre Médical Evangelique, Nyankunde, Congo

1 Halsey NA, Sommer A, Henderson DA, Black RF Ethics and international research. BMJ 1997;315:965-6. (18 October.)
Kenyan statutory body was unaware of study

EDITOR-The editorial by Halsey et al adds to the debate on the ethics of doctors from the United States carrying out research in women with HIV infection in developing countries. ${ }^{1}$ One of the studies that Halsey et al referred to was apparently carried out in Kenya, ${ }^{2}$ yet to date the Medical Practitioners and Dentists Board, the statutory body which oversees professional and ethical standards in the country, was not aware of the study. It seems that researchers from the United States have taken advantage of the current lack of relevant legislation to collaborate with a group of Kenyan doctors who may have been persuaded to see things the visitors' way. The Medical Practitioners and Dentists Board will be pushing for legislation to make it mandatory that all medical research is discussed fully by the relevant local professionals to ensure that decisions that are compromised by the undue enthusiasm of researchers are not allowed and that patients' rights are protected.

The argument put forward by Halsey et al is flawed and unsustainable, and I doubt that the research referred to would have been approved by the board with the explanation that patients receiving placebo treatment were receiving the medical care normally available in their own country, true though this assertion may be. I cannot imagine approval, for instance, of a Kenyan study in which half of the patients receive antimalarial treatment while the other half takes placebo in a district where the lack of these drugs is common. Such research takes advantage of patients whose only fault is that they happen to live in countries where research laws are lax and the quality of medical care is poor. The medical profession the world over must resist such double standards at all costs. There are ample opportunities in a country such as Kenya to carry out ethically acceptable research.

Richard Baraza Chairman

Medical Practitioners and Dentists Board, Nairobi, Kenya

1 Halsey NE, Sommer A, Henderson DA, Black RE Ethics and international research. BMJ 1997;315:965-6. (18 October.)

2 Lurie P, Wolfe SM. Unethical trials of interventions to reduce perinatal transmission of the human immunodeficiency virus in developing countries. $N$ Engl J Med 1997;337:853-6.

\section{Potential enticement of placebo trials needs to be debated}

EDITOR-In their editorial Halsey et al considered the ethical debate on placebo controlled trials of treatments designed to prevent maternal-infant transmission of HIV. ${ }^{1}$ The key to this debate is whether a trial that offers a $50 \%$ probability of receiving inactive treatment (placebo) and a $50 \%$ probability of receiving active treatment (but of unknown benefit) is interpreted as a 1 in 2 chance of causing harm or a 1 in 2 chance of therapeutic gain. This depends on two factors: the strength of evidence that the active treatment will be more effective and the standard of current treatment. For such a 
trial to be ethical (in any setting) there must be genuine uncertainty as to whether active treatment is truly better. However, the standard of current treatment varies widely. A $50 \%$ chance of an active treatment when the alternative is no treatment might be considered an undue inducement to enter the trial.

This issue is not confined to expensive drugs or to the developing world. In a recent European placebo controlled trial of antihypertensive treatment over $40 \%$ of the participants were recruited from eastern Europe $^{2}$; in the United Kingdom, trials of anticholinergic agents for Alzheimer's disease are attractive to patients and their families as the cost of such drug treatment prohibits their routine use

The issue of placebo controlled trials and their potential for undue enticement when standard treatment is not necessarily best treatment is worthy of broad debate, not just within the medical profession. Currently, uncertainty remains about whether such trials represent a form of medical benevolence or are evidence of medical imperialism.

Martin J Landray Lecturer in clinical pharmacology Clinical Pharmacology Section, Department of Medicine, University of Birmingham, Queen Elizabeth Hospital, Birmingham B15 2TH

1 Halsey NA, Sommer A, Henderson DA, Black RE Ethics and international research. BMJ 1997;315:965-6 (18 October.)

2 Staessen JA, Fagard R, Thijs L, Celis H, Arabidze GG, Birkenhäger WH, et al for the Systolic Hypertension in Europe (Syst-Eur) Trial Investigators. Randomised doubleblind comparison of placebo and active treatment for blind comparison of placebo and active treatment for
older patients with isolated systolic hypertension. Lancet 1997;350:757-64

\section{Authors' reply}

EDITOR-From our endorsement of the placebo controlled trials, Edi-Osagie and Edi-Osagie incorrectly assumed that we are conducting the trials. Their alternative trial would be flawed because HIV diagnostic testing (as well as treatment) is not routinely available for women outside the trials; some women would be denied the right to participate in a trial that could reduce their risk of transmitting HIV, and non-participants could differ from participants in key factors.

The ongoing trials are designed to benefit developing countries as the short course regimens will not be implementable in the United States, where women are treated with two or three antiretroviral drugs before, during, and after pregnancy. ${ }^{1}$

Review committees at universities and national agencies in developed and developing countries have determined that these studies are consistent with international ethical guidelines, which Lurie and Wolfe misinterpreted. ${ }^{2}$ The trial sponsored by the United States Centers for Disease Control and Prevention in Thailand is being conducted with the full approval of Thai and American government authorities ( $\mathrm{P}$ Nieburg, personal communication). Future misunderstandings could be minimised by writing guidelines in clear language. De Cock has summarised the potential harmful effect on public perception of the misguided and misleading criticisms raised by Lurie and Wolfe. ${ }^{3}$
Contrary to Lurie and Wolfe's claim, Edward Connor (cochairman) and Richard Gelber (biostatistician) report that their ACTG 076 study did not determine the efficacy of short course treatment, and they support the need for additional trials (personal communication).

Lurie and Wolfe have repeatedly misrepresented the rationale for changes in a planned study in Ethiopia. This trial will not begin until some placebo controlled trials have been completed. If a short course is shown to be effective the Ethiopian study will determine whether supplementing the regimen will provide additional protection. No one knows if the short course regimens will be effective. For example, recent data from Thailand showed that transmission rates were $15 \%$ in those who received zidovudine and $16 \%$ in those who received placebo (P Phanupak, fourth international conference on AIDS in Asia and the Pacific, Manila, October 1997). Without a placebo group, investigators could have falsely concluded that the short course zidovudine treatment was effective since earlier data from Bangkok showed a $25 \%$ transmission rate in untreated women (N Shaffer, conference on paediatric AIDS in Thailand: a public health and social dilemma, Bangkok, February 1995).

Burdon appropriately calls attention to the high current cost of zidovudine. The Joint United Nations Programme on HIV/ AIDS (UNAIDS) has initiated efforts to reduce these costs in an innovative collaboration with pharmaceutical manufacturers and the governments of developing countries (press release, 5 November 1997). Policies for the use of limited resources in developing countries must be guided by scientifically sound studies of practical interventions. The ongoing placebo controlled trials should provide the necessary data

Neal A Halsey Director

Alfred Sommer Dean

Robert E Black Department chair

Department of International Health, School of Hygiene and Public Health, Johns Hopkins University, 615 North Wolfe Street, Baltimore MD 21205, USA

1 US Public Health Service Task Force. Recommendation for use of antiretroviral drugs during pregnancy for maternal health and reduction of perinatal transmission of human immunodeficiency virus type 1 in the United States. Federal Register 1997;62:36809-23.

2 Council for International Organisations of Medica Sciences-World Health Organisation. International ethical Sciences-World Health Organisation. International ethical guidelines for biomedical resea De Cock KM. Publicity, politics, and public health: the case of placebo controlled trials for the prevention of countries. International AIDS Society Newsletter 1997 Dec 1.

Obtaining informed consent for trials in Africa is possible

EDITOR-Informed consent may indeed be hard to achieve in populations struggling to achieve even adequate routine medical services. ${ }^{1}$ The responsibility of the ethics committees and of researchers working in such situations must be to safeguard rights that would be more eloquently reasoned in industrialised nations. We would like to share some observations from a trial in Lusaka, Zambia.
The trial protocol-approved by ethics committees in both Lusaka and London and supported by the World Health Organisation and the Department for International Development-entailed inviting patients to undergo HIV testing in order to enter a randomised, placebo controlled trial of preventive treatment against tuberculosis. From August 1992 to July 1994, 1053 subjects were recruited. All received counselling from trained counsellors before and after their HIV test, and after a discussion about the trial they were asked to sign a consent statement outlining their rights to withdraw and explaining the inclusion of a placebo arm.

Altogether 115 patients, despite joining the study, never returned to the clinic after their first visit. This led us to review the recruitment procedure to give subjects a chance to discuss the issues further with family and friends before returning for randomisation. Three patients were recruited on two separate occasions with an interval of many months, which suggests that they had not clearly understood the trial design, although it is also possible that they were trying to maximise the chance of receiving active treatment

A subset of 185 of those recruited had already undergone voluntary HIV counselling and testing and came to the trial clinic to be enrolled. ${ }^{2}$ Significantly more of these subjects completed the course of treatment $(160 / 185(86 \%)$ v $617 / 868$ (71\%), $\mathrm{P}<0.0001)$ and remained in follow up throughout the study $(138 / 160 \quad(86 \%)$ v $475 / 617(77 \%), \mathrm{P}<0.05)$

The ethical and practical difficulties of randomised controlled trials in resource poor settings with a high seroprevalence of HIV infection should not prevent such trials from being conducted. Trials in industrialised countries rarely address questions that will lead to appropriate interventions in the developing world.

Having more widespread facilities for voluntary HIV testing and counselling in Africa would lead to a larger number of subjects who had considered their serostatus and were in a better position to decide to join clinical trials. Not only do such subjects maximise the chances of clear results being obtained but they also minimise the ethical dilemmas of researchers pressurised to recruit adequate sample sizes.

Peter Godfrey-Faussett Coordinator, AMBART Project

Alwyn Mwinga Lecturer

Maria Hosp Research affiliate

Department of Medicine, University Teaching Hospital, PO Box 50110, Lusaka, Zambia peter@zamnet.zm

Rachel Baggaley Research coordinator Kara Counselling and Training Trust, Lusaka

Maria Quigley Lecturer

John Porter Senior lecturer

Department of Infectious and Tropical Diseases, London School of Hygiene and Tropical Medicine, London WC1E 7HT

1 Mhlongo SWP, Mdingi GV. Informed consent. BMJ 1997; 315:252. (26 July.) 
2 Godfrey-Faussett P, Baggaley R, Mwinga A, Hosp M, Porter J, Luo N, et al. Recruitment to a trial of tuberculosis preventive therapy from a voluntary counselling and testing centre-implications for implementation. Trans $R$ Soc Hyg Trop Med 1995;89:354-8.

\section{Serum samples in clinical study were manipulated}

EDITOR-Smith has announced that a Committee on Publication Ethics had been formed as a response to the increase in misconduct in research, as, for example, in the case reported by Dyer in the same issue. ${ }^{12}$ Pharmaceutical companies should be anxious to detect and disclose any cases of research fraud because they may affect the credibility of the companies' clinical drug studies. We present here an example to show that methods are available for this purpose. A pharmaceutical manufacturer asked us to investigate the case, which turned out to be one of serious fraud.

Some measurements made on serum samples sent in by an investigating doctor had been questioned in a central laboratory. We were asked to check the identity of these 10 pairs of serum samples ( $1 \mathrm{a}$ and $1 \mathrm{~b}, \ldots$, $10 \mathrm{a}$ and $10 \mathrm{~b}$ ). The test protocol stated that each pair of samples came from one patient.

After high speed centrifugation we obtained enough cells to determine the DNA markers amelogenin, ${ }^{3}$ humTH01, humACTBP2, and humFIBRA (microsatellites survey). ${ }^{4}$ The supernatant was used to investigate the serum markers GC, AHSG, $\mathrm{HP}$, and TF with isoelectric focusing. ${ }^{5}$ In none of the 10 cases could the samples a and $\mathrm{b}$ be assigned to the same patient. In four cases a change of sex was noted (amelogenin $\mathrm{XX} \rightarrow \mathrm{XY}$ ). Moreover, all serum samples showed three or four alleles in one or several markers so that pooled serum from at least two people was present. In four cases the serum came from at least three people. To provide an example, the table gives the results for samples $5 \mathrm{a}$ and $5 \mathrm{~b}$ and $6 \mathrm{a}$ and $6 \mathrm{~b}$. There is every reason to believe that these were intentional manipulations.

With the great number of clinical studies being performed, it is difficult to find out whether there are other undetected, though less evident, cases of this kind. In the present

Genetic markers in two pairs of serum samples ( $5 a$ and $5 b ; 6 a$ and $6 b$ ) claimed to originate from patients 5 and 6

Code of sample

\begin{tabular}{|c|c|c|c|c|}
\hline \multirow[b]{2}{*}{ Marker } & \multicolumn{2}{|c|}{5} & \multicolumn{2}{|c|}{6} \\
\hline & $5 a$ & $5 b$ & $6 a$ & 6b \\
\hline$\overline{\mathrm{GC}}$ & $1 \mathrm{~S}$ & $2-1 S$ & $1 S-V$ & $1 \mathrm{~S}$ \\
\hline AHSG & $2-1$ & $2-1$ & $2-1$ & $2-1$ \\
\hline$\overline{\mathrm{HP}}$ & 1S-2FS-1F & $2 \mathrm{FS}$ & 1S-2FS & $2 \mathrm{FS}$ \\
\hline$\overline{\mathrm{TF}}$ & $\mathrm{C}_{1}$ & $\mathrm{C}_{1}$ & $C_{1}-C_{2}-D$ & $\mathrm{C}_{1}-\mathrm{C}_{2}$ \\
\hline HumTH0-1 & 6-9.3 & $6-9$ & $9-9.3$ & $6-9-9.3$ \\
\hline \multirow[t]{2}{*}{ HumFIBRA } & $19-20$ & $23-25$ & $21-22-25-26$ & $21-22$ \\
\hline & $21-22^{*}$ & & & \\
\hline \multirow[t]{2}{*}{ HumACTBP $_{2}$} & $62.2-65.2$ & $59.2-60.2$ & $59.2-63.2$ & $59.2-63.2$ \\
\hline & $61.2^{*}$ & $61.2-63.2-64.2$ & & 66.2 \\
\hline Amelogenin & $X Y$ & $X X$ & $X Y$ & $X Y$ \\
\hline
\end{tabular}

*Weak signal.

case, an irregularity was assumed owing to the extremely improbable findings in the determination of relevant laboratory variables.

To prevent cases such as this one, random identity controls should be established by means of forensic markers as part of clinical drug studies, before publication. Thus potential misconduct would be deterred. The use of the above mentioned serum markers in combination with three or four DNA markers allows detection of almost all irregularities of the kind described in this case.

R Szibor Professor of natural sciences

W Kuchheuser Physician

C Luley Professor of medicine

D Krause Professor of forensic medicin

Institute for Forensic Medicine, University of

Magdeburg, D-39120 Magdeburg, Germany

1 Smith R. Misconduct in research: editors respond. BMJ 1997;315:201-2. (26 July.)

2 Dyer C. Consultant struck off over research fraud. $B M$ 1997;315:205. (26 July.)

3 Sullivan KM, Mannucci A, Kimpton PA, Gill P. A rapid and quantitative DNA sex test: fluorescence-based PCR analysis of $\mathrm{X}-\mathrm{Y}$ homologous gene amelogenin. Bio Techniques 1993;15:636-41.

4 Perez-Lezaun A, Calafell F, Mateu E, Comas D, Bosch F, Bertranpetit J. Allele frequencies for 20 microsatellites in a worldwide population survey: Hum Heredity 1997;47:189-96.

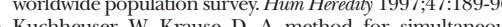
Kuchheuser W, Krause D. A method for simultaneou determination of group-specific component (GC) an le electic focusing

\section{Rebound sodium and water retention occurs when diuretic treatment is stopped}

EDITOR-Walma et al claim that patients should continue to take diuretics if they retain sodium and water on stopping diuretic treatment. ${ }^{1}$ However, if diuretics are suddenly withdrawn in patients with a normal salt intake there will be rebound retention of sodium and water. This is because the compensatory mechanisms that are induced to maintain sodium balance in the face of the diuretic are still acting several days after the effect of the diuretic has worn off.

There are two ways of trying to mitigate the rebound retention of sodium and water that occurs on stopping diuretic treatment. One is to gradually reduce the dose to noth- ing. The other (and better way) is to place the patient on a low sodium diet so that only a small amount of sodium can be retained when diuretic treatment is stopped. ${ }^{3}$

Many patients are being unnecessarily treated with diuretics, which are not without adverse effects. When diuretics are withdrawn the patient develops rebound retention of sodium and water and oedema, which convinces the doctor that the diuretics are necessary, and the patient is then committed to a lifetime exposure to diuretics. $^{2}$ Some patients with heart failure do need to continue with diuretic treatment. But, even in these patients, if salt intake is reduced diuretics may be unnecessary or a lower dose may suffice.

Walma et al need to repeat their study allowing for the above before concluding that all patients taking diuretics require them.

Constaninos G Missouris Senior registrar in cardiology

Graham A MacGregor Professor of cardiovascular medicine

Blood Pressure Unit, Department of Medicine,

St George's Hospital Medical School, London SW17 0RE

1 Walma EP, Hoes AW, van Dooren C, Prins A, van der Does E. Withdrawal of long term diuretic medication in elderly patients: a double blind randomised trial. BMJ 1997; 315:464-8. (23 August)

2 MacGregor GA, Markandu ND, Roulston JE, Jones JC, de Wardener HE. Is "idiopathic" oedema idiopathic? Lancet 1979; i:397-400.

3 Missouris CG, Cappuccio FP, Markandu ND, MacGregor

GA. Diuretics and oedema: how to avoid rebound sodium retention. Lancet 1992;339:1546.

\section{Should stroke medicine be a separate subspecialty?}

\section{Perhaps units should focus on clinical problems rather than diseases}

EDITOR-Bath et al have argued cogently for a subspecialty of stroke medicine. ${ }^{\text {I I venture }}$ to suggest a modification of their proposal. They state correctly that during the past 20 years knowledge of stroke (its course, pathophysiology, effective interventions, etc) has increased greatly. The knowledge base seems likely to continue to grow in the next few years. It is, however, much less certain that there will be an equivalent widespread improvement in service provision. Something needs to be done about this. The creation of a stroke specialty is one option, and the suggestion needs careful consideration. Three points are perhaps worth making.

Firstly, disease specific specialties within medicine have not found favour in Britain, the preference being for generalism with an interest in a particular system. Secondly, the creation of a subspecialty, as suggested, would have appreciable implications well outside the area of stroke (for example, on training requirements and deployment of hospital beds). Thirdly, the three phases of strokeprevention, acute care, and rehabilitationinvolve different skills. For example, few consultants are fully knowledgeable about the pathophysiology of acute cerebral ischaemia and about rehabilitation. 
An opportunity now exists to refashion some parts of medical practice, with an increased emphasis on clinical problems rather than diseases. Such an approach would involve identifying what various diseases have in common with each other. In the field of stroke medicine several points might be worthy of debate:

Prevention-The risk factors for coronary artery disease and stroke are similar. Perhaps what is needed is a locality based cardiovascular disease prevention service dealing with such common problems as hypertension, cardiac arrhythmias, and transient ischaemic attacks.

Acute management-Major hospitals might in future have an acute brain damage unit dealing not only with stroke but also perhaps with traumatic brain injury and acute encephalopathies. Such units should be in a good position to deal with a wide range of problems (for example, cerebral ischaemia, raised intracranial pressure, convulsions, respiratory difficulties, and nutritional problems).

Rehabilitation-Patients with stroke do better when looked after on a stroke unit. But does this need to be a unit only for patients with stroke? Can't other patients with rehabilitation needs (for example, with brain injury) be looked after on the same ward? Do we really need separate facilities for each category of disease?

Bath et al highlight the need for more medical expertise in the field of stroke. But is a disease oriented specialty the best way of achieving this objective? Data and evidence are needed.

R Langton Hewer Professor

Department of Social Medicine, University of Bristol, Bristol BS8 2PR

Bath P, Lees K, Dennis M, Smithard D, Bone I, Grosset D, et al. Should stroke medicine be a separate subspecialty? BMJ 1997;315:1167-8. (1 November.)

Stroke services should be coordinated by physicians who are expert and interested

EDITOR-I would endorse the suggestion of Bath et al that stroke medicine become a separate medical subspecialty. ${ }^{1}$ Having trained in general/internal medicine and neurology, I find that my full time hospital appointment as a neurologist has evolved into one that deals solely with stroke medicine, and I am more than occupied. This is not only because of the size of the problem and the increasing demand for specialised stroke services but also because of the complexity of stroke management.

As Bath et al indicate, stroke is heterogeneous in its clinical presentation, pathology, aetiology, prognosis, and response to treatment. The medical management requires skill in many aspects of general medicine and its subspecialties, including geriatric medicine, neurology, cardiology, haematology, immunology, genetics, radiology, intensive care, pharmacology, rehabilitation, clinical trials, clinical epidemiology, and public health medicine; it also requires an understanding of specific aspects of vascular surgery and neurosurgery. In addition, it demands skills in organising and coordinating a multidisciplinary stroke team of nurses and allied health professionals.

There is now little doubt that outcome in patients with stroke who have been managed in an organised stroke unit by a multidisciplinary team coordinated by an enthusiastic and well trained specialist in stroke medicine is better than that in patients managed in general medical wards. ${ }^{2}$

If we are to continue to strive to minimise the burden of stroke on our patients, their carers, and the community we need to provide organised stroke services that are coordinated by physicians who are expert as well as interested. The advances in research in stroke medicine in the past decade have led to sound evidence based guidelines for stroke management and to large increases in the number of physicians becoming interested and involved in stroke care. The time is now right for the royal colleges of physicians in the United Kingdom and other countries such as Australia to draw on the growing experience and skill of current stroke specialists to train formally the stroke medicine physicians of the future.

Graeme J Hankey Consultant neurologist

Royal Perth Hospital, Perth, Australia

gihankey@cyllene.uwa.edu.au

1 Bath P, Lees K, Dennis M, Smithard D, Bone I, Grosset D, et al. Should stroke medicine be a separate subspecialty? BMJ 1997;315:1167-8. (1 November.)

2 Stroke Unit Trialists' Collaboration. Collaborative systemic review of the randomised trials of organised inpatien (stroke unit) care after stroke. BMJ 1997;314:1151-9.

Future consultants in stroke medicine should also rotate through psychiatry

EDITOR-Nowhere in the article on the creation of a stroke subspecialty do Bath et al refer to the neuropsychiatry of stroke. ${ }^{1}$ Nor, indeed, are any of the authors psychiatrists. This represents an important omission as $30-50 \%$ of patients with stroke will have depression within two years of their initial stroke, ${ }^{23}$ and this will vary in intensity from depressive symptoms to full blown major depression with all its potentially devastating consequences. Not only does depression directly threaten the patient's life and relationships but it also interferes with rehabilitation and recovery from stroke and therefore contributes to morbidity and mortality. The severity of the depression is not necessarily associated with the degree of disability due to the stroke ${ }^{4}$; in many patients with minor to moderate disability due to the stroke, depression remains undiagnosed and untreated because the doctor regards their symptoms as "understandable" after their stroke. ${ }^{5}$ This is one of the commonest clinical errors in the management of depression after stroke.

The choice of treatment for such patients requires considerable psychiatric knowledge, given that patients may have other complicating illnesses and psychotropic drugs may affect the damaged brain in unpredictable ways. Expertise is likewise required to differentiate depression after stroke from other affective syndromes associated with stroke, notably emotional lability and aprosody. Also, although depression is the commonest and most serious neuropsychiatric complication of stroke, most other psychiatric symptoms can be caused by it and require specialist care in their own right. ${ }^{4}$

The authors should add psychiatry to the specialties through which an embryonic stroke consultant might rotate. That any reference to the neuropsychiatry of stroke can be omitted from such an article supports the authors' case for the creation of another subspecialty. Equally, given the complexity of the issues, it is an argument for a more inclusive multidisciplinary approach to the problem

R A Rosin Locum consultant geriatric psychiatrist St Charles's Hospital, London W10 6DZ

1 Bath P, Lees K, Dennis M, Smithard D, Bone I, Grosset D, et al. Should stroke medicine be a separate subspecialty? BMI 1997;315:1167-8. (1 November)

2 Starkstein SE, Robinson RG. Neuropsychiatric aspects of Starkstein SE, Robinson RG. Neuropsychiatric aspects of stroke. In: Coffey EC, Cummings JL, eds. Textbook of geriatric neuropsychiatry.

3 Cummings JL, Trimble MR. Concise guide to neuropsychiatry and behavioural neurology. Washington, DC: American Psychiatric Press, 1995:180-2

4 Starkstein SE, Robinson RG. Affective disorders and cerebral vascular disease. Br J Psychiatry 1989;154:170-82. 5 Rouchell A, Pounds R, Tierney JG. Depression. In: Rundell JR, Wise MG, eds. Textbook of consultation liaison psychiatry. Washington, DC: American Psychiatric Press, 1996:323.

\section{Where is scientific evidence supporting EU policy on BSE and pharmaceuticals?}

Editor-Bowser is right to attempt to provide an update of European Union (EU) policies regarding bovine spongiform encephalopathy and pharmaceuticals. ${ }^{1}$ Unfortunately his letter misses the main concern of my earlier letter ${ }^{2}$ : where is the evidence supporting any of the EU's policies on bovine spongiform encephalopathy and pharmaceuticals?

Bowser is wrong to state that amendments to the EU directive on spongiform encephalopathy will not affect drugs. The commission's decision of 30 July (not 29 July as he stated) explicitly mentions the words "pharmaceuticals" and "medicines" (for example, in points 18 and 19). ${ }^{3}$ The EU's Committee on Proprietary Medicinal Products warned in its report on human medicinal products affected by decision $97 / 534 / \mathrm{EC}$ that if the commission's decision was enforced then more than half the drugs currently on EU markets would have to leave the market before January 1998.

Bowser is incorrect in stating that "a broader commission decision on the use of materials in the food chain was adopted on 29 July 1997." Article 2 of the commission's decision of 30 July 1997 states: "the use of specified risk materials for any purpose shall be prohibited." The decision, if applied, affects items such as medicines, foods, cosmetics, and candles. Contrary to Bowser's statement, if the decision of 30 July came into effect gelatin would be affected. Why else would the US meat rendering industry prepare to file a $£ 64 \mathrm{~m}$ lawsuit against the commission's decision? 
The commission stated in July that it was banning specified risk materials in pharmaceuticals for human consumption from the EU markets from 1 January 1998. The definition of material involved has broadened to include transmissible spongiform encephalopathies (TSEs).

Bowser is wrong to state that the commission's proposals to amend directive 75/318/ EEC (not 75/18/EEC) have been suspended. The decision has been revised. Article 8 of the commission's decision states: "This decision shall be reviewed in the light of new scientific information with regard to the risk of exposure to TSEs resulting from infectivity in other animal species, age categories or materials. Where necessary this decision shall be amended." The ban on products containing specified risk materials or materials derived from specified risk materials is now planned to come into effect on 1 April 1998. Already some drug companies are changing the source of materials for their products.

These are the facts. But where is the scientific evidence supporting any of this EU policy?

Alan Earl-Slater Senior lecturer in health economics Department of Medicines Management, Keele University, Keele, Staffordshire ST5 5BG

1 Bowser DRB. EU directive on bovine spongiform encephalopathy will not affect drugs. BMJ 1997;315:551. (30 August.)

2 Earl-Slater A. Bovine spongiform encephalopathy threatens drugs in European Union. BMJ 1997;315:426. (16 August.)

3 European Commission. Commission decision of 30 July on the prohibition of the use of material presenting risks as the prohibition of the use of material presenting risks as
regards transmissible spongiform encephalopathies. Brussels:

4 Earl-Slater A. A study of pharmaceutical policies in the EU. Policy Studies 1997;18:251-67.

\section{CJD was not diagnosed until eight months after organ donor's death}

EDITOR-Christie reported on the circumstances leading to the independent inquiry that was ordered after the corneas and sclera from a woman were used for transplantation before a postmortem examination found that she had Creutzfeldt-Jakob disease. ${ }^{1}$ Unfortunately, he made several inaccurate statements.

In particular, the article said that the doctors involved with the patient before her death suspected that she might have Creutzfeldt-Jakob disease. This suggestion is not borne out by the facts. At no time during the donor's life, including during the days immediately before her death from carcinoma of the lung, was Creutzfeldt-Jakob disease suspected or listed in the differential diagnosis of her condition. It is untrue, therefore, to report that "despite these fears [that she might have Creutzfeldt-Jakob disease] no action was taken to prevent Mrs Hamilton's corneas and sclera being used in transplants." The disease was diagnosed only eight months after the patient's death, during an ongoing routine histopathological surveillance project on brain tissue.
I suggest that the interpretation of the circumstances surrounding this complicated and regrettable incident is best left to the scrutiny of the planned independent inquiry without prior comment, which is likely to be ill informed.

G D Morrice Consultant ophthalmologist Stirling Royal Infirmary NHS Trust, Stirling Royal Infirmary, Stirling FK8 2AU

1 Christie B. Inquiry ordered after organ donor found to have CJD. BMJ 1997;315:1485. (6 December.)

\section{Acute otitis media in children}

\section{Reappraisal of management of acute otitis media is required}

Editor-Majeed and Harris's editorial on the treatment of acute otitis media in children contains an intellectual non sequitur. ${ }^{1}$ While acknowledging that over three fifths of children are pain free at 24 hours and that serious complications are rare, they fail to appreciate the trade off between risk and benefit by endorsing the current practice of antibiotic prescribing.

To a concerned parent whose child has acute otitis media, information can be conveyed in these terms: over half of children with earache are pain free after 24 hours provided symptomatic treatment is given; and for every child who experiences diminished pain between two to seven days, three other children will have vomiting, diarrhoea, or a rash without deriving any benefit from an antibiotic. ${ }^{2}$ Even this statement ignores other hazards associated with antibiotic treatment: the medicalisation of a self limiting condition, ${ }^{3}$ the increase in antibiotic resistance over time, ${ }^{4}$ and the opportunity costs of prescribing drugs.

The authors are correct in calling for further studies that elucidate prognostic factors associated with a poor outcome. Current evidence from clinical trials, however, does not support the current policy of antibiotic prescribing. Contrary to the conclusions of the editorial, a reappraisal of the management of acute otitis media seems to be required.

Tom Fahey Senior lecturer

Deborah Sharp Professor

Division of Primary Health Care, University of

Bristol, Bristol BS8 2PR

1 Majeed A, Harris T. Acute otitis media in children. BM 1997;315:321-2. (9 August.)

2 Del Mar C, Glasziou P, Hayem M. Are antibiotics indicated as initial treatment for children with acute otitis media? A meta-analysis. BMI 1997-314:1526-9.

3 Little P, Gould C, Williamson I, Warner G, Gantley M, Kinmonth AL. Reattendance and complications in
Kintle P, Gould C, Willamson I, Warner G, Gantley M, randomised trial of prescribing strategies for sore throat: randomised trial of prescribing strategies for sore throat:
the medicalising effect of prescribing antibiotics. $B M J$ the medicalising effect of

1997;315:350-2. (9 August.)
Arason VA, Kristinsson KG, Sigurdsson JA, Stefansdotti 4 Arason VA, Kristinsson KG, Sigurdsson JA, Stefansdotti
G, Molstad S, Gudmundsson S. Do antimicrobials increase G, Molstad S, Gudmundsson S. Do antimicrobials increas
the carriage rate of penicillin resistant pneumococci in children? Cross sectional prevalence study. BMJ 1996 313:387-91.

5 Froom J, Culpepper L, Jacobs M, DeMelker RA, Green LA, van Buchem L, et al. Antimicrobials for acute otitis media? A review from the International Primary Care Network. BMJ 1997;315:98-102.

\section{Authors' reply}

EDITOR-We agree that antibiotics offer only limited benefits when used to treat children with acute otitis media, and we did not endorse the current practice of antibiotic prescribing in our editorial. Our own practice is to explain to parents of children with acute otitis media what the benefits and risks of antibiotic treatment are. We have found that once we have done this, most parents are willing to forgo antibiotics. This has led to a substantial decline in our rate of prescribing of antibiotics for acute otitis media without any increase in complications or decrease in patients' satisfaction. We are pleased to see that Fahey and Sharp advocate a similar management strategy. The Dutch experience suggests that such an approach can be implemented without leading to an increase in serious complications. ${ }^{12}$ We, however, are not as critical as Fahey and Sharp about the continued use of antibiotics.

Firstly, most of the data on the side effects of antibiotics in Del Mar et al's metaanalysis $^{3}$ came from only one trial, ${ }^{4}$ and we do not think it reasonable to propose a change in practice on the basis of just one study. Secondly, the recommendations of previous meta-analyses have sometimes been overturned by the findings of well designed randomised controlled trials. ${ }^{5}$ Thirdly, before writing our editorial we asked local general practitioners how they would manage children with acute otitis media. Most said they would continue to use antibiotics and gave several reasons for doing so. These included the limitations of previous randomised controlled trials and uncertainty about the diagnostic criteria used in them; a concern that a lower level of antibiotic prescribing could lead to an increase in the incidence of conditions such as mastoiditis; and a belief that bacterial infections should be treated with antibiotics. Hence the statement in our editorial that "most general practitioners are likely to continue to treat children with acute otitis media with antibiotics" is not a non sequitur, nor is it a recommendation that current practice should continue unaltered. It is simply a statement of fact.

Changing clinical behaviour is complex. General practitioners are unlikely to change their prescribing habits if they have major doubts about the validity of the evidence presented to justify the proposed change in practice.

\section{Azeem Majeed Senior lecturer}

Tess Harris Lecturer

Division of General Practice and Primary Care, St George's Hospital Medical School, London SW17 0RE

1 Van Buchem FL, Peeters MF, van't Hof MA. Acute otiti media: a new treatment strategy. BMJ 1985;290:1033-7. 2 Froom J, Culpepper L, Jacobs M, DeMelker RA, Green LA, van Buchem L, et al. Antibiotics for acute otitis media? A review from the International Primary Care Network. BMJ 1997;315:98-102.

3 Del Mar CB, Glasziou P, Hayem M. Are antibiotics indicated as initial treatment for acute otitis media? A meta-analysis. BMJ 1997;314:1526-9.

4 Burke P, Bain J, Robinson D, Dunleavy J. Acute red ear in children: controlled trial of non-antibiotic treatment in general practice $B M J 1991 \cdot 303: 558-69$.

5 Egger M, Davey Smith G. Misleading meta-analysis. BMJ 1995:310:753-4. 


\section{SSRIs may well be best treatment for elderly depressed subjects}

EDITOR-In his review of mental health in old age Macdonald advocates the use of dothiepin as a first line antidepressant. ${ }^{1} \mathrm{He}$ suggests that the selective serotonin reuptake inhibitors should usually be reserved for cases in which tricyclic antidepressants fail or are contraindicated. Although it is impossible in a brief review article to cover fully the advantages and disadvantages of different drugs, we think it important to highlight that, as in younger patients, rational choice of a first line antidepressant in elderly people is difficult and controversial. This is particularly so because of a dearth of antidepressant studies in late life, especially in frail, physically ill patients and those who are cognitively impaired. ${ }^{2}$

Macdonald states that selective serotonin reuptake inhibitors may be slow to act. Even if this is the case, the slow titration to an effective dose that is necessary with tricyclic antidepressants (up to 42 days, according to the regimen Macdonald gives for dothiepin) may delay the onset of antidepressant effect to a much greater extent. Furthermore, discontinuation of treatment is more common with tricyclics ${ }^{3}$ and, if it leads to a change in antidepressant, will cause a further delay in effective treatment. Therefore, treatment with selective serotonin reuptake inhibitors is likely to lead to many depressed patients being treated effectively sooner than if they were given other drugs. In general practice, selective serotonin reuptake inhibitors are more likely than tricyclic antidepressants to be prescribed in a therapeutic dose in elderly patients. ${ }^{4}$ Undertreatment is an important reason for poor prognosis in some studies of elderly subjects, ${ }^{5}$ and this may be one of the most important reasons for advocating the use of selective serotonin reuptake inhibitors by general practitioners.

Current research has not shown clear superiority of one antidepressant over another in terms of efficacy. The choice of a first line agent therefore remains difficult, controversial, and often idiosyncratic. Further comparisons between antidepressants in elderly patients are needed. We believe that rational choice is best made after consideration of factors such as history of tolerability of and response to a particular agent; type of depression (agitated or retarded); concurrent drug treatment and possible drug interactions; compliance; concurrent physical illness; and liability to particular side effects such as postural hypotension, cognitive impairment, and sedation. After such consideration, selective serotonin reuptake inhibitors may well be selected as first line treatments for many elderly depressed subjects.

Richard J Porter Clinical lecturer in psychiatry John T O'Brien Senior lecturer in old age psychiatry Department of Psychiatry, University of Newcastle, Royal Victoria Infirmary, Newcastle upon Tyne NE1 4LP
1 Macdonald AJD. ABC of mental health: mental health in old age. BMJ 1997;315:413-7. (16 August.)

2 Anstey K, Brodaty H. Antidepressants and the elderly: double blind trials 1987-1992. Int Geriatric Psychiatry 1995; 10:265-79.

3 Martin RM, Hilton SR, Kerry SM, Richards NM. General practitioners' perceptions of the tolerability of antidepressant drugs: a comparison of selective serotonin reuptake inhibitors and tricyclic antidepressants. BMJ 1997; 314:646-51.

4 Orrell M, Collins E, Shergill S, Katona C. Management of depression in the elderly by general practitioners. I Use of antidepressants. Fam Pract 1995:12:5-11.

5 Baldwin B. The outcome of depression in old age. Baldwin B. The outcome of dep

\section{Writing to authors of systematic reviews elicited further data in $17 \%$ of cases}

EDITOR-Roberts and Schierhout have emphasised the importance of writing letters to authors of trials in order to locate additional references for systematic reviews. ${ }^{1}$ We have recently completed nine reviews related to the treatment of tardive dyskinesia, which are available in the Cochrane Library. We identified 49 trials that had data suitable for our reviews, and a further 72 trials that still require either clarification of design issues or extraction of data on the prespecified outcomes. Altogether 176 trials were excluded. During the course of the review we wrote 133 letters, which we sent to authors in North America $(\mathrm{n}=72)$, Europe $(\mathrm{n}=44)$, and other countries $(\mathrm{n}=17)$. The date of the publications ranged from 1970 to 1997 . We report here the response rates to our letters after an interval ranging from 10 to 18 months.

To date we have received no reply to 70 letters, while another 12 were returned to sender (current location of author unknown); we received 51 replies. The authors were able to supply at least some data suitable for meta-analysis in 23 cases; 26 authors indicated that they were unable to extract the required data, while data extraction is still pending in two cases. Twenty three of the authors who replied had changed their address, so their previous institutions must have forwarded our letters. The relation between the decade of publication of the study and the status of the reply was examined. Contrary to expectation, there was no indication that authors of older publications were less likely to reply than authors of more recent publications $\left(\chi^{2}=0.78, \mathrm{df}=2, \mathrm{P}=0.68\right.$ (table) $)$. The probability of reply was evenly distributed across 10 regional groups $\left(\chi^{2}=7.21, \quad \mathrm{df}=9\right.$, $\mathrm{P}=0.62$ ).

Because of the mobility of the research community, it is not surprising that so many letters were returned to sender. With the increased use of email and the potential for automated rerouting of email, the probability

Numbers of letters sent out that did and did not elicit replies

\begin{tabular}{lccc} 
& $\mathbf{1 9 7 0 - 9}$ & $\mathbf{1 9 8 0 - 9}$ & $\mathbf{1 9 9 0 - 7}$ \\
\hline Reply & 12 & 29 & 10 \\
\hline No reply & 20 & 41 & 21 \\
\hline
\end{tabular}

of locating authors may improve. There are two main points of interest: firstly, over a third of our letters resulted in replies that helped with completion of the reviews, and, secondly, letters sent to addresses derived from papers published in the 1970s were no less likely to elicit replies than letters sent to addresses derived from more recent publications.

J McGrath Associate professor of psychiatry

G Davies Scientist

Queensland Centre for Schizophrenia Research, Wolston Park Hospital, Wacol, Q4076, Australia

K Soares Visiting associate professor

Department of Psychiatry, Federal University of São Paulo, Brazil

1 Roberts I, Schierhout G. The private life of systematic reviews. BMJ 1997;315:686-7. (13 September.)

\section{Trial of prescribing strategies for sore throat}

\section{Complications of sore throat are not rare}

EDITOR-We agree with Little et al that the symptom sore throat is one of the most common presenting complaints in primary care and that there is a tendency to overprescribe antibiotics. ${ }^{1}$ We do not, however, agree with the second key message of their paper, which states that complications of sore throat are rare. In any otolaryngology department the symptom sore throat accounts for a considerable number of urgent admissions. In our department in the past six months, 340 emergency admissions were recorded. Among these we identified 70 in which sore throat was the primary complaint. This means that there were an average of 2.69 admissions a week for this symptom. These patients are usually ill with high temperature, dysphagia, or a complication that has developed because of either lack of treatment or an insufficient or inadequate dose of antibiotics. They then require intensive intravenous antibiotic treatment, management of fluid balance, and sometimes surgical intervention.

We were surprised that the authors included patients with quinsy in the randomisation. Quinsy is a well defined clinical and bacteriological entity that may lead to serious complications in terms of airway obstruction, and spread through the constrictor muscles of the pharynx could produce a parapharyngeal abscess. ${ }^{23}$ Quinsy usually needs surgical incision and drainage and often needs intensive intravenous antibiotic treatment. In our opinion, it should not be left untreated.

The authors have not identified the proportion of their patients who developed complications who needed referral to hospital. In our experience, some would have needed admission. Complications of sore throat and tonsillitis are not rare, and some can be life threatening. These complications include parapharyngeal abscess, retropharyngeal abscess, neck abscess, tonsillar haemorrhage, cervical necrotising fasciitis, septicaemia, rheumatic fever, and glomerulonephritis. ${ }^{3}$ 
Although in principle we agree that most patients with sore throats are not at risk, we think that such patients should be carefully assessed and treated on their own merits. Those with a high risk of developing complications, such as children and elderly patients, and those who are immunocompromised or have systemic diseases should be given special attention.

Ricard Simo Senior registrar

Avinash Pahade Senior house officer

Antonio Belloso Senior house officer

Department of Otolaryngology and Head and

Neck Surgery, Royal Preston Hospital, Preston PR2 4HT

1 Little PS, Gould C, Williamson I, Warner G, Gantley M, Kinmonth AL. Reattendance and complications in a randomised trial of prescribing strategies for sore throat: the medicalising effect of prescribing antibiotics. $B M$ J 1997;315:350-2. (9 August.)

2 Prior A, Montgomery P, Mitchelmore I, Tabaqchali S. The microbiology and antibiotic treatment of peritonsillar abscesses. Clin Otolaryngol 1995;20:219-23.

3 Hibbert J. Acute infection of pharynx and tonsils. In: Stell PM, ed. Scott-Brown's otolaryngology. 5th ed. Vol 5. London: Butterworth, 1987:76-98.

\section{Authors' reply}

EDITOR-Simo et al have misunderstood the criteria for including patients in our trial. Patients with quinsy were not eligible; the complications quoted relate to the follow up period. $^{1}$

How common are serious complications such as quinsy, and can they be prevented by prescribing antibiotics for patients who are not very ill? Assessment of how common cases of quinsy are must take account of the population denominator. Only one case of quinsy occurred in 434 patients who had no or delayed treatment. On the assumption that this was not a chance finding and that half of all cases of quinsy are preventable (generous assumptions), then roughly 868 patients would need treatment to prevent one case of quinsy. If we assume that $33 \%, 20 \%$, or $10 \%$ of subsequent quinsy is preventable then 1302,2170 , or 4340 patients respectively would need to be treated to prevent one case. A "mega-trial" would be needed to estimate the true effect.

Computerised data from 16000 patients in our two surgeries (an inner city surgery and a market town surgery-about 7000-8000 presentations of sore throat ${ }^{2}$ ) document 23 patients with quinsy or pre-quinsy, of whom only nine presented with a prior sore throat (six received antibiotics, which did not prevent the quinsy). Thus most quinsy in otolaryngology departments probably presents de novo and is not "preventable." Simo et al list other complications, which are also rare-for example, a general practitioner has roughly a 1 in 5 lifetime chance of preventing a case of rheumatic fever or glomerulonephritis. ${ }^{2}$

These rare complications must be balanced against the complications of prescribing which do not present to-and thus may be "invisible" to-otolaryngology departments; these include rash, diarrhoea, recurrence, and antibiotic resistance (all common); anaphylaxis in 1-2 in 5000 cases; and death from anaphylaxis in 1 in 50000 (similar to the likelihood of preventing rheumatic fever if antibiotics are given). ${ }^{2}$ A major "side effect" is the medicalising effect of prescribing: one patient will return to the surgery for every nine patients treated, with a larger long term effect due to reinforcement.

General practitioners must balance the large, quantified medicalising effects of prescribing in the climate of increasing demand and antibiotic resistance with the poorly quantified possibility that a few patients may benefit from reduced complications if they do prescribe, taking into account the serious side effects of prescribing. Thus until better evidence is available for clinical targeting to minimise complications for patients who are not very ill, either not prescribing or delaying prescribing is likely to be the most effective and efficient management.

Paul Little General practitioner Wellcome training fellow Ian Williamson Senior lecturer in primary care Clare Gould Research assistant Ann-Louise Kinmonth Professor of primary medical care

Madeleine Gantley Anthropologist

Primary Medical Care, Aldermoor Health Centre, Southampton SO16 5ST

Greg Warner General practitioner

Nightingale Surgery, Romsey SO16 5ST

1 Little PS, Williamson I, Warner G, Gould C, Gantley M, Kinmonth AL. An open randomised trial of prescribing strategies for sore throat. BMJ 1997:314:722-7.

2 Little PS, Williamson IW. Sore throat management in general practice. Fam Pract 1996;13:317-21

\section{Words matter}

\section{The term "side effects" trivialises} unwanted effects

EDITOR-Smart points out that patients with kidney failure may be distressed by the term "end stage kidney failure." CancerBACUP, a charity that provides information, counselling, and support for all those affected by cancer, has had similar feedback from patients with cancer. Recently, when revising our booklet "Understanding cancer of the prostate," we sought the advice of, among others, members of a prostate cancer support group. They expressed the view that the term "side effects," widely used in association with treatment, trivialised what they considered to be important, unwanted effects: impotence and incontinence. We have changed our booklet accordingly.

Jean Mossman Chief executive

CancerBACUP, London EC2A 3JR

1 Smart DJ. Words matter. BMJ 1997;315:1021. (18 October.)

\section{Classifications are useful}

EDITOR-Although I can sympathise with Smart's dislike of the term "end stage kidney failure,"1 he should let nephrologists keep their useful classification of renal failure. ${ }^{2}$
Kidney failure alone will not do. The adjectives tell us, our patients, and colleagues about urgency and prognosis-for example, in "acute reversible renal failure." He will have worked out that end stage renal failure means complete irreversible renal failure and may be grateful that the previous terminology is no longer used: in the days before dialysis and transplantation, the condition was referred to cruelly but, alas, accurately as "terminal renal failure."

C G Winearls Consultant nephrologist Oxford Renal Unit, The Churchill, Oxford OX3 7LJ

1 Smart DJ. Words matter. BMJ 1997;315:1021. (18 October.) 2 El Nahas AM, Winearls CG. Chronic renal failure and its treatment. In: Weatherall DJ, Ledingham JGG, Warrell DA Oxford textbook of medicine. 3rd ed. Vol 3. Oxford: Oxford University Press, 1996.

\section{Other diseases are not prefixed by "end stage"}

EDITOR-Three cheers for Smart, who objected to the use of the term "end stage kidney failure." ${ }^{1}$ A similarly derogatory term used frequently in the United States is "end stage renal disease." We don't speak of "end stage heart disease," "end stage lung disease," or "end stage brain disease." So why should we use such a term as "end stage renal disease," especially with the advent of haemodialysis, peritoneal dialysis, and renal transplantation, all of which have completely changed the prognosis of this disease?

Tsung $\mathbf{O}$ Cheng Professor of medicine Department of Medicine, George Washington University, 2150 Pennsylvania Avenue NW, Washington, DC 20037, USA

1 Smart DJ. Words matter. BMJ 1997;315:1021. (18 October.)

\section{Advice to authors}

We receive more letters than we can publish: we can currently accept only about one third. We prefer short letters that relate to articles published within the past four weeks. We also publish some "out of the blue"letters, which usually relate to matters of public policy.

When deciding which letters to publish we favour originality, assertions supported by data or by citation, and a clear prose style. Letters should have fewer than 400 words (please give a word count) and no more than five references (including one to the BMJ article to which they relate); references should be in the Vancouver style. We welcome pictures.

Letters, whether typed or sent by email, should give each author's current appointment and full address. Letters sent by email should give a telephone and fax number when possible. We encourage you to declare any conflict of interest. Please send a stamped addressed envelope if you would like to know whether your letter has been accepted or rejected.

We may post some letters submitted to us on the world wide web before we decide on publication in the paper version. We will assume that correspondents consent to this unless they specifically say no.

Letters will be edited and may be shortened. 